\title{
Die Wiederkehr der Systemkritik
}

\author{
Hauke Brunkhorst (brunk@uni-flensburg.de) \\ Europa-Universität Flensburg, Germany
}

Endlich wird die Systemfrage wieder gestellt. Stefan Lessenich, bis vor Kurzem noch Vorsitzender der Deutschen Gesellschaft für Soziologie, hat ein glänzend geschriebenes Buch publiziert, das weit über das Fach hinaus gelesen wird. Es könnte das theoriemüde, in kleinteiligem Empirismus verdämmernde Fach befeuern, sich seiner gesellschaftskritischen Geschichte zu erinnern, die über weite Strecken an weltverändernder Praxis und einem progressiven Reformismus orientiert war.

Um angesichts der absehbaren, wenn auch weithin verdrängten ökonomischen, politischen, sozialen und ökologischen Katastrophen des 21. Jahrhunderts die „Waffen der Kritik“ Marx) zu schärfen, muss man nur Kant und Marx in konsequenter Anwendung des kategorischen Imperativs zusammenführen.

Spätestens seit 1989 leben wir in einem nach außen geschlossen kapitalistischen Weltsystem. Es funktioniert nach der von Marx entdeckten Logik der Externalisierung der Kosten eines Wirtschaftssystems, das den technischen Fortschritt in eine ständig wachsende, „ungeheure Warenansammlung" (Marx 1953) verwandelt. Sie lässt alles, was bis dahin produziert wurde, als ebenso lächerlich erscheinen wie den Zeitgenossen des technischen Fortschritts die mythischen Heroentaten der antiken Welt. „Wo bleibt (...) Jupiter [der Blitzeschleuderer] gegen den Blitzableiter, und Hermes [der Schutzgott der Fernreisenden] gegen den Crédit mobilier? (...) Was wird aus der Fama [der Göttin des Ruhms und des Gerüchts] neben Printinghouse square?" fragte sich schon Marx zu einer Zeit, als vom modernen Kapitalismus nur in einigen wenigen, nachts erstmals beleuchteten Weltstädten und winzigen, aber rasant wachsenden Industrieregionen etwas zu sehen war (Marx 1953: 30f.).

Die Produktivität des Systems ist mit einer nicht minder ungeheuren Destruktivität verschwistert, die es gegen sich und seine Umwelt richtet. Die gewaltigen Kosten, die dabei entstehen, kann das System aber nur um den Preis des Stillstands, der es und alles, was an ihm hängt und von ihm lebt, vernichten würde, selbst tragen. Das Kapital muss die Kosten seiner erweiterten Reproduktion den Lohnabhängigen und der gesamten Gesellschaft aufbürden, die ihm mit tausenden von Bail-outs immer wieder auf die Beine hilft.

Schon früh wurde der „Übelstand“ des globalen Südens zur kausalen Bedingung des „Wohlstands“ im globalen Nordwesten (43). „Ohne Armutskapitalismus kein Wohlstandskapitalismus“ (192). 
Das liegt aber nicht nur an der finanzgetriebenen Weltwirtschaft, sondern auch an der ebenso unvollständig wie einseitig globalisierten Staatsgewalt. Globalisiert wurde nur die vorgeblich rein technische Seite der Politik, die sachlich effektiven policies, die politische Führer und Experten unter sich ausmachen, nicht aber die im demokratischen Prozess bestimmte Politik, die dadurch erst zum gefundenen Fressen für die Pseudoalternativen des identitären Populismus wurde. ${ }^{1}$ Durch die Externalisierung der Demokratie verlieren die entpolitisierten Institutionen die politische Macht, etwas anders durchzusetzen als marktkonforme Politik, die weder demokratisch noch im Selbsterhaltungsinteresse des politischen Systems ist, was dem Rechtsopulismus Tür und Tor öffnet.

Erst jetzt gilt, dass das Wachstum unter null sinken und den unkontrollierten Sinkflug des kapitalistischen Weltsystems einleiten würde, wenn die, die im Wohlstand leben, die im Übelstand nicht mehr ausrauben (Outsourcing), ihnen den ungeklärten und strahlenden Giftmüll nicht mehr vor die Haustür kippen und ihren unstillbaren Hunger auf Bodenschätze nicht mehr durch Landgrapping, das grüne Agrarlandschaften in Wüsten verwandelt, stillen würden.

Dass das so bleibt, kann man nicht wollen, sagt der kategorische Imperativ. Im Wohlstand zu leben, läßt sich, auch bei Beachtung aller moralischen Regeln politischer Korrektheit nicht verallgemeinern. Was immer wir tun, das kapitalistische Weltsystem „lenkt das soziale Handeln strukturell in eine Richtung, die gerade nicht verallgemeinerungsfähig ist" (79). Das gilt aber auch umgekehrt, denn der unkontrollierte Sinkflug des kapitalistischen Weltsystems würde die, die im Norden wie im Süden unter ihm leiden, mit sich reißen. Auch das kann man nicht wollen, wenn das, was man wollen kann, universalisierbar sein soll. So sitzen wir in der Falle. Aus ihr heraus führt, wie die Anwendung des kategorischen Imperativ auf die negative Dialektik von Wohl- und Übelstandsgesellschaft zeigt, keine Moralisierung, nur Systemkritik (80f). Die Verhältnisse sind so, dass jede Moral, die das System nicht überwindet, nur immer weiter in die Katastrophe führen würde. Das wußte übrigens auch Kant, der deshalb die einzige Hoffnung moralischen Handelns in einem radikalen, progressiven Reformismus sah, wenn nicht gar im Geschichtszeichen der Revolution.

Die schlechter weggekommenen Bewohner des Nordens sind nicht nur besser weggekommen als die besser weggekommenen des Südens (sieht man einmal von der winzigen Zahl der Superreichen $a b$, die es fast überall gibt), sondern sie schulden auch ihren noch so bescheidenen Wohlstand dem Übelstand des Südens (55).

Trotzdem hat sich ihre Lage in den letzten 40 Jahren dramatisch verschlechtert, wie Oliver Nachtwey in seiner brillanten Studie zur regressiven Moderne zeigt.

Während nur die oberen 10 Prozent der Wohlstandsgesellschaften in dieser Zeit erhebliche Zuwächse an Einkommen und Vermögen verzeichnen konnten, haben alle übrigen sozialen Schichten z.T. massive Einbußen hinnehmen müssen. Dazu kommen Austeritätspolitik, fortschreitendende Privatisierung des Bildungs- und Rentensystems, regressive Arbeitsmarktreformen,

1 Europa ist ein besonders instruktives, aber keineswegs allein dastehendes Beispiel (Offe 2016: 114ff.). 
schwindende Gewerkschaftsmacht und die Vernichtung akademischer Arbeitsplätze durch artifizielle Intelligenz, welche zwei Drittel der Bevölkerung in eine lebenslang prekäre Existenz versetzen, aus der sie für sich und ihre Kinder immer weniger Hoffnung auf Besserung schöpfen können.

Die Wiederkehr massiver sozialer Ungleichheit macht, wie Nachtwey zeigt, die großen Errungenschaften der Emanzipation der Frauen, Farbigen und Homosexuellen von Jahrhunderte, wenn nicht Jahrtausende alter Ungleichbehandlung und Unterdrückung wieder zunichte. Für die schwarze, jüdische, vorbestrafte, wohnungslose Homosexuelle in der Peripherie von Paris, Brüssel oder Mailand hat die neu gewonnen Freiheit keinen „fairen Wert“ (Rawls 1979), denn sie kann sich dem misogynen, rassistischen, antisemitischen und homophoben Milieu gar nicht entziehen, das die schlecht bezahlte, aber schwer bewaffnete lokale Polizei des Ghettos ebenso prägt wie die meisten seiner depravierten Bewohner. Wiederum sind die einen ohne Schuld besser weggekommen und die andern ohne Schuld schlechter weggekommen. Aber die Gerechtigkeit bleibt trotzdem auf der Strecke, denn keiner hat ein Recht, besser weggekommen zu sein (Rawls 1979: 94/121ff.).

\section{References}

Lessenich, S., (2016). Neben uns die Sintflut. Die Externalisierungsgesellschaft und ihr Preis. Berlin: Hanser Berlin. 224 S.

Marx, K., (1953). Grundrisse der Kritik der politischen Ökonomie. Berlin: Dietz.

Nachtwey, O., (2016). Die Abstiegsgesellschaft. Über das Aufbegehren in der regressiven Moderne. Berlin: Suhrkamp. 264 S.

Offe, C., (2016). Europe entrapped. Oxford: Polity.

Rawls, J., (1979). Eine Theorie der Gerechtigkeit. Frankfurt: Suhrkamp. 